\title{
A ORGANIZAÇÃO INFORMACIONAL DO ACERVO DO MUSEU DE ARTE CONTEMPORÂNEA DA UNIVERSIDADE DE SÃo PAULO
}

\author{
Camila Aparecida Silva'
}

\begin{abstract}
Resumo
Este artigo situa o Museu de Arte Contemporânea da Universidade de São Paulo no debate sobre documentação museológica, tema recente no Brasil. Poucos são os acervos de arte brasileiros que seguem alguma padronização na organização de suas coleções. No entanto, nenhum deles adota um protocolo consolidado tais como os elaborados internacionalmente, - que gera problemas como o desconhecimento sobre 0 seu acervo e a morosidade nas atividades de exposição e recuperação de informação. Entende-se que o uso de sistemas de documentação e a adoção de normas de organização informacional são essenciais para preservar e disseminar a informação de coleções artísticas.
\end{abstract}

\section{Palavras-chave}

acervo museológico, documentação museológica, MAC USP, museus de arte, organização da informação.

\begin{abstract}
This paper aims to situate Contemporary Art Museum of University of São Paulo in the debate on museum documentation that is a recent subject in Brazil.There are a few Brazilians museum which to use some method to organize their collections. However, none of that museums to adopt a consolidated protocol, for instance, the standards developed internationally. Consequently, there are some issues for the museums, such as the unawareness of their own collections, and the slowness in the exhibition activities and in the information retrieval. Therefore, it is considered that to use documentation systems and to adopt protocols are fundamental actions to preserving and to disseminating information on art collections.
\end{abstract}

\section{Keywords}

information organization, museum documentation, art museums, MAC USP, museum collections.

\section{Introdução}

O objetivo deste artigo é analisar os desafios enfrentados pelo Museu de Arte Contemporânea da Universidade de São Paulo (MAC USP) na organização e recuperação da informação de seu acervo, composto de obras de arte moderna e contemporânea, com a finalidade de identificar os processos de documentação museológica adotados pelo museu no período entre 1948 e o primeiro semestre de 2015.A organização e a recuperação informacional de obras de arte são realizadas a partir de processos de representação descritiva (catalogação) e representação temática (indexação), com o propósito de criar e padronizar registros, facilitar o acesso à informação e disseminar o acervo. $A$ catalogação envolve a descrição de dados da obra, tais como autor, data, técnica, 
material e procedência. Já a indexação atribui termos (descritores) para descrever o conteúdo de uma obra. Para a atribuição desses termos é necessário o uso de um tesauro, elaborado a partir de uma terminologia. Entende-se que um museu, além de ser um espaço expositivo, deve ser visto também como um centro de informação, tal como proposto por Otlet $(2007)^{2}$ e mais recentemente discutido por Bevilacqua (20l4). Nesta posição, o museu deve fornecer material para subsidiar pesquisas, disponibilizar informações sobre as coleções e promover a extroversão dos objetos.

A documentação museológica torna possível, segundo Machado (20I4), a identificação e a localização de uma obra, o intercâmbio de seus dados (processo denominado interoperabilidade), a obtenção de informações sobre sua procedência e a orientação de procedimentos. Ademais, a documentação permite ampliar pesquisas sobre a história do museu e de seu acervo. Para uma documentação efetiva, são fundamentais o inventário, que deve ser feito periodicamente, a elaboração de um manual de catalogação, a padronização de processos e o uso de um sistema de gestão de acervo apropriado, trabalho desenvolvido em conjunto por historiadores de arte e por documentalistas. $O$ acesso à informação de um acervo deve ser pensado para uso interno, destinado aos funcionários, e para uso externo, destinado ao público em geral. Há também o público formado por pesquisadores que faz uso de informações mais detalhadas sobre as coleções que compõem o acervo.

A documentação museológica de acervos de arte no Brasil é um assunto recente, ao contrário do que acontece no cenário internacional, em que essa discussão remonta ao final do século XIX, quando foi criada a primeira associação de profissionais de museus, a Museums Association, em 1889. Essa discussão passou a ter força no Brasil a partir de 2013, quando a cidade de São Paulo passou a sediar os treinamentos do Comitê Internacional para Documentação do Conselho Internacional de Museus (CIDOC ICOM) e a literatura internacional da área começou a ser traduzida para o português, tais como as diretrizes do CIDOC e as normas Spectrum, cujas versões brasileiras foram publicadas em 2014 e, em 2016, a Introdução aos vocabulários controlados. Até então, o Brasil foi cenário de iniciativas isoladas no que diz respeito a esse tema. Entre essas iniciativas estão a criação do Thesaurus para acervos museológicos, em 1987, e a sistematização e informatização do acervo do Museu Nacional de Belas Artes do Rio de Janeiro, com o desenvolvimento do sistema de gerenciamento DONATO, no ano de 1992.

Além dos benefícios elementares propiciados por uma documentação adequada e constantemente atualizada, como o controle do acervo e a recuperação da informação sobre os objetos, outro motivo que faz o MAC USP necessitar de uma documentação consistente se encontra no fato de ser um museu universitário e, assim, estar essencialmente vinculado às atividades de pesquisa. Pesquisa e documentação se retroalimentam, isto é, a documentação fornece dados que subsidiam as pesquisas, ao passo que os resultados de pesquisas trazem novas informações sobre os objetos museológicos que serão incorporadas aos seus registros. Dessa forma, os registros ficam mais completos. Os desafios de documentação museológica enfrentados pelo MAC USP e identificados no período de estudo foram a descontinuidade da publicação de catálogos gerais

2 Cf. OTLET, 2007. Essa obra foi originalmente escrita em 1934. 
do acervo; a inexistência de uma política documental e de um manual de procedimentos de documentação; a não adoção de diretrizes de documentação; 0 uso de um sistema de gerenciamento de coleções obsoleto; e a ausência de um ambiente on-line de acesso ao acervo, para fins de disseminação. Esses desafios serão expostos adiante. Contudo, antes, será visto como se deu a formação do acervo do Museu³.

\section{O Museu de Arte Contemporânea da Universidade de São Paulo}

O MAC USP tem sua origem no antigo Museu de Arte Moderna de São Paulo (MAM), inaugurado em 1948, na Rua Sete de Abril, número 230, sob a direção de Léon Degand ${ }^{4}$. Este museu era o desejo de um grupo de intelectuais e foi concretizado pelo italiano Francisco Matarazzo Sobrinho, também conhecido como Ciccillo. A coleção inicial do antigo MAM foi formada por doações de Ciccillo Matarazzo5, por doações de Nelson Rockefeller, que consistiram em 13 obras no ano de 1946 e 25 gravuras no ano de 1950, e por obras advindas das Bienais de São Paulo, que teve sua primeira edição realizada em outubro de 1951 .

O tratamento informacional do acervo do antigo MAM foi feito por meio de uma lista datilografada das obras, pelo uso de fichas catalográficas em papel - uma para cada item do acervo - e pelo registro das peças em dois livros de tombo. A lista datilografada foi elaborada por Eva Lieblich Fernandes 6 , possivelmente no ano de $195 \mathrm{I}$, segundo entrevista ${ }^{7}$. As primeiras fichas catalográficas foram feitas provavelmente em 1959, isto é, depois de mais de dez anos da inauguração do Museu. Já os livros de tombo, de acordo com Magalhães (2012), foram feitos provavelmente entre 1960 e 1962. No primeiro livro, as obras estão divididas por nacionalidade, nas categorias brasileira e estrangeira. Em cada categoria, as obras estão classificadas pelo sobrenome do autor. $\bigcirc$ segundo livro de tombo está dividido em dois fichários, um deles apresenta a relação de pinturas e esculturas do acervo e o outro, a relação de gravuras, que, neste caso, inclui todas as obras feitas em papel.

O antigo MAM costumava fazer catálogos de suas exposições. No entanto, não foi feito nenhum catálogo geral do acervo. Apesar de haver certo controle sobre as obras, conforme apresentado, os registros e as fichas catalográficas não apresentavam informações completas. O único inventário do acervo do antigo MAM foi produzido em 1963, com o auxílio de Etelvina Chamis Rosas, em razão da transferência do acervo do Antigo MAM para a USP, de modo que este inventário teve um caráter administrativo.

3 No texto, Museu com a inicial maiúscula se refere ao MAC USP.

4 Entre os diretores do antigo MAM esteve Wolfgang Pfeiffer, que mais tarde foi diretor do MAC USP, no período entre 1978 e 1982.

5 Pesquisas recentes revelam que Ciccillo Matarazzo adquiriu um conjunto de obras com a intenção de formar o antigo MAM e não um acervo pessoal, conforme se pensava, o que significa que a formação do acervo do museu se deu de maneira racionalizada Cf. MAGALHÄES, Ana G. (Org.) Classicismo, realismo, vanguarda: pintura italiana no entreguerras. São Paulo: MAC USP, 2013.

6 Eva L. Fernandes era funcionária das empresas Matarazzo no ano de 1947 e passou a trabalhar também no antigo MAM até o ano de 1952, desenvolvendo atividades na empresa e no museu ao mesmo tempo. Somente em I95I o museu contratou uma secretária própria, Etelvina Chamis Rosas.

7 FERNANDES, Eva Lieblich. Depoimento. São Paulo, jun.20I0. Entrevista concedida à Ana Gonçalves Magalhães. 2010. 


\section{O acervo do MAC USP}

O antigo MAM foi extinto em 1962 e seu acervo, doado à Universidade de São Paulo, deu origem ao MAC USP no ano seguinte. Entre as razões para o fechamento do museu estavam o tempo destinado ao planejamento e à realização das Bienais de São Paulo, que ocupava quase que integralmente a equipe do museu, e a demanda por recursos materiais e financeiros, de modo que o museu ficava em segundo plano. A doação das obras do antigo MAM para o MAC USP se dividiu em três etapas. A primeira consistiu na doação da coleção de Francisco Matarazzo Sobrinho, composta de 429 obras e realizada em setembro de 1962. A segunda etapa foi a doação de 19 obras do casal Francisco Matarazzo Sobrinho e Yolanda Penteado, em 1963, mas efetivada dez anos depois. E, por último, a doação de I.243 obras do antigo MAM, em 1963.

Walter Zanini foi o primeiro diretor do MAC USP. Ele ocupou esse posto por quinze anos, entre 1963 e 1978. O Museu, com um quadro de funcionários pequeno, foi instalado provisoriamente no Pavilhão da Bienal, no Parque lbirapuera, afastado da comunidade acadêmica, confirmando desde o princípio o desinteresse da Universidade pelo patrimônio adquirido, conforme afirma Chiarelli $(201 \mathrm{I})^{8}$.

A gestão de Zanini esteve voltada para a atualização do acervo, que no ano de 1978 era composto de 5.274 obras. A quantidade de obras incorporadas ao acervo nas gestões posteriores, precedida pelo nome dos diretores do Museu foram:Wolfgang Pfeiffer (I978-1982) - 69l obras; Aracy Amaral (I 9821986) - 4I3 obras; Ana Mae Barbosa (1986-1993) - 974 obras; Lisbeth Ruth Rebollo Gonçalves (1994-1998) - 370 obras; José Teixeira Coelho Neto (19982002) - 299 obras; Elza Ajzenberg (2002-2006) - 31 obras; Lisbeth Ruth Rebollo Gonçalves (2006-20 I0) - I I 8 obras; e Tadeu Chiarelli (20I0-20 I4) - 448 obras9. Até o final de 2014, o acervo totalizava mais de II mil objetos, entre obras de arte moderna e obras de arte contemporânea. A partir desses dados, constata-se que a documentação é um processo contínuo, tendo em mente que novas obras são adquiridas e que aquelas que já estão sob propriedade do Museu precisam ter sua catalogação revisada e atualizada periodicamente.

\section{A documentação do acervo do MAC USP}

A seguir, serão apresentados os estágios da documentação do acervo do MAC USP, que inclui os dois projetos de revisão catalográfica, a informatização do acervo, a catalogação de obras de arte contemporânea e a publicação dos catálogos gerais. No período entre 1963 e 1982 não foram encontradas evidências de processos consolidados no que se refere à organização informacional das coleções $^{10}$. Esses processos começaram a aparecer apenas na gestão de Aracy

8 Tadeu Chiarelli é docente no departamento de Artes Plásticas da Escola de Comunicações e Artes (ECA USP), ex-diretor do MAC USP e assumiu a direção artística da Pinacoteca do Estado de São Paulo entre 2015 e maio de 2017.

9 Dados fornecidos pela documentalista do MAC USP, Michelle Alencar, em maio de 2014.

10 Ainda sobre a primeira fase de documentação do Museu, repercute negativamente o fato de parte dos documentos referentes às obras ter sido dispersa durante a transferência do acervo para a Universidade. Esses documentos encontram-se distribuídos no atual Museu de Arte Moderna de São Paulo (MAM), reinaugurado em 1968, na Fundação Bienal, no MAC USP e no Museu de Arte de São Paulo Assis Chateaubriand (MASP). O Setor de Arquivo do MAC USP, onde todos esses documentos deveriam estar arquivados, foi estruturado somente em 1996. Ainda assim, até aproximadamente o ano de 2005, os processos de aquisição das obras, 
Amaral, conforme será mostrado adiante.

Nos anos iniciais do MAC USP, Neusa Zanini, esposa de Walter Zanini, contribuiu com a organização da informação sobre as obras. Mais tarde, essa função passou para Daisy Peccinini, que contou com o apoio de Elvira Vernaschi e Harumi Yamagishi. No final do ano de 1972 o acervo somava $2.04 \mathrm{I}$ obras. Em 1973 foi realizado o primeiro inventário do acervo do MAC USP, que teve como finalidade a elaboração do primeiro catálogo geral do acervo, publicado no mesmo ano. $\mathrm{Na}$ década de 1980, o país passava pelo processo de abertura política, o que deu impulso à organização de acervos. A Universidade estava sendo informatizada e o MAC USP passou por uma reordenação institucional, que teve impacto nas atividades documentárias das coleções. Assim, houve no Museu a elaboração de processos básicos de documentação com certa padronização de campos descritores, a tentativa de uso de terminologias e a criação de dossiês de artistas, conforme aponta Sônia Salsztein (2015)".

A gestão de Aracy Amaral, de 1982 a 1986, foi decisiva para a sistematização da documentação do acervo devido à criação da Divisão Científica, cuja coordenação ficou sob a responsabilidade de Lisbeth Ruth Rebollo Gonçalves ${ }^{12}$, durante três anos. Em 1983, quando o Museu passou a se localizar dentro da USP, em um espaço provisório, teve início o resgate do arquivo morto e a primeira revisão da catalogação atribuída a Aida Cristina Cordeiro, especialista em arquivos. Com essa revisão foi possível dar início à elaboração do segundo catálogo geral, no ano de 1984. Neste momento, o acervo contava com 4.280 obras registradas, a maior parte de origem nacional, e 580 obras de arte conceitual. Até então, as fichas catalográficas do antigo MAM, datadas de ca.1959, eram reutilizadas pelo MAC USP, isto é, novas informações sobre as obras foram sobrescritas à mão. $O$ primeiro modelo de ficha catalográfica do MAC USP foi criado somente em 1985 para atender à revisão catalográfica, cujo propósito era atualizar os registros das obras para que fossem transferidos das fichas catalográficas em papel do antigo MAM para um sistema informatizado.

A informatização do acervo do MAC USP teve início em agosto de 1986, ano em que foi finalizada a primeira revisão catalográfica do acervo ${ }^{13} \mathrm{e}$ implantada a Seção de Catalogação, por Cristina Cabral e Marcos Rezende. Cabral acompanhou esse processo, primeiro como estagiária e em seguida como funcionária efetiva, e foi a responsável pela criação do banco de dados, elaborado na linguagem de programação Dbase 3 e atualizado para o Dbase 3 Plus, em 1989. O banco de dados contribuiu para a sistematização da catalogação do acervo e foi desenvolvido para uso interno, isto é, para atender, em um prazo menor, às demandas da equipe. No entanto, a elaboração do software do Museu ocorreu circunstancialmente, em caráter de urgência ${ }^{14}$, sem anteriormente ter havido

que ficaram sob posse da Reitoria, eram descartados seguindo uma tabela de temporalidade, ou seja, tais documentos foram submetidos a um tratamento inapropriado, uma vez que são de guarda permanente.

I I Sônia Salzstein é docente no departamento de Artes Plásticas da ECA USP. Ela integrou a equipe do Museu entre 1985 e 1987, primeiro como assistente técnica e mais tarde como coordenadora do setor de acervo da Divisão Científica. Além dela, destaca-se também as passagens de Lilian Tone, Silvia Cajado, Sophia Telles, Pieter Tjabbes e Antonella Mosca no Museu.

12 Lisbeth Ruth Rebollo Gonçalves é docente na ECA USP e do Programa de Pós-Graduação Interunidades em Estética e História da Arte, oferecido pelo MAC USP.

I3 CABRAL, Cristina. Depoimento. São Paulo: MAC USP, dez.20I4. Entrevista. 2014.

I4A demanda da Seção de Catalogação era alta e os processos manuais atrasavam o atendimen- 
uma reflexão sobre a realização dessa prática, sem uma política institucional efetivamente implantada e sem verba destinada para este fim, conforme afirma Magalhães (20l0). Embora o impacto inicial da informatização tenha sido positivo à época, proporcionando agilidade nos processos, o banco de dados tornou-se obsoleto a longo prazo, pois sem uma equipe com treinamento adequado, o Museu, com a importância de seu acervo, estava distante das discussões internacionais sobre normatização de documentação e gestão de coleções. Conforme exposto, a primeira revisão catalográfica do acervo ocorreu em 1983. Entretanto, após a saída de Aracy Amaral, em 1986, as demais gestões não priorizaram a documentação das obras, interrompendo as ações que poderiam ter tido como resultado a definição de políticas documentais do MAC USP.

Em 1992, o MAC USP ganhou uma sede própria na Cidade Universitária, próxima do restaurante universitário central e da moradia estudantil.Ali, foi implantada uma sala de catalogação ${ }^{15}$ e instalados um arquivo deslizante, um computador, um escâner e uma impressora adquiridos com verba externa, por meio de projeto elaborado por Cristina Cabral e submetido à Fundação de Amparo à Pesquisa do Estado de São Paulo (Fapesp), em 199716. Durante a reforma do Museu, no início dos anos 2000, Cabral fez a migração do sistema Dbase para - Microsoft Access. A segunda versão do banco de dados foi, então, implantada no ano de 200I.A preocupação com as atividades de documentação do acervo por parte da gestão do Museu reacendeu vinte anos depois da primeira revisão. Nesse ínterim, as demais ações de atualização do sistema ocorreram por iniciativa de Cabral, pois até aproximadamente o ano de 2005, os pesquisadores do Museu não tinham autonomia para tomada de decisões, antes concentrada na figura do diretor, o que dificultava a criação de políticas documentais.

Em 2006, Lisbeth Ruth Rebollo Gonçalves reassumiu a direção do MAC USP e junto com a então chefe da Divisão de Pesquisa em Arte,Teoria e Crítica, Cristina Freire ${ }^{17}$, exerceu papel determinante para a documentação do Museu, ao identificar a necessidade de atualização da catalogação do acervo. Com isso, em 2008 tem início a segunda revisão catalográfica do acervo com a contratação de Ana Gonçalves Magalhães, que ficou responsável pelo projeto denominado "Reavaliação Crítica da Catalogação do Acervo do MAC USP"'18. Como consequência desse projeto, segundo Magalhães (20I2; 20I5), o MAC USP passou a usar como critério de seleção para análise detalhada de uma obra de arte o conjunto de coleções no qual foi adquirido - o lote - em vez de analisar cada obra isoladamente ou pela classificação do suporte, prática comum no antigo MAM.Além disso, a reflexão crítica passou a orientar o trabalho de revisão dos registros das obras, sendo estabelecido, portanto, como um princípio de organização.

Ainda nesse período, o programa de gerenciamento de coleções estava to de pedidos, daí a necessidade de informatização das coleções (CABRAL, 20|4).

I5 De acordo com Cabral (20I4), embora a Seção de Catalogação tenha sido criada em I986, não havia um espaço físico próprio para a execução das atividades.

16 CABRAL, 2014.

17 Curadora e pesquisadora do acervo de Arte Conceitual.

I8 Este projeto contou com a contribuição de alunos bolsistas da Universidade, supervisionados por Ana G. Magalhães e pelo documentalista Fernando Piola, são eles Andréa Cortez Alves, César Augusto de Alencar, Claudia Colli e Maria Lívia N. Goes. Entre suas atribuições estavam a documentação das exposições ocorridas no Museu e a digitalização das fichas catalográficas do antigo MAM, entre os anos de 2012 e 2013. As fichas em papel encontram-se arquivadas. 
com desempenho comprometido e precisava ser atualizado para atender às necessidades informacionais internas. Sugerida pela equipe do Museu em 2010, a proposta de migração dos registros para a versão mais recente do Microsoft Access, no qual o sistema foi construído, não foi aprovada, pois geraria conflitos na consistência dos dados. A admissão pelo Museu da analista de sistemas Marilda Giafarov, em 2012, possibilitou o estudo de um conjunto de softwares comerciais específicos para o gerenciamento de coleções, pois a escolha de um sistema envolve a análise de suas funcionalidades, a facilidade de uso, os custos da licença e de sua manutenção.Assim, chegou-se ao consenso de que o sistema MuseumPlus da ZetCom era o mais adequado às necessidades do MAC USP'9. No entanto, com a crise da Universidade a partir do ano de 20I4, que tinha João Grandino Rodas como reitor (20l0-20l4) e Hugo Segawa ${ }^{20}$ como diretor do Museu, o processo de compra do software foi suspenso.

A versão do banco de dados construída no Microsoft Access 2003 apresentou outros agravantes, seu suporte técnico foi interrompido em abril de 2014 e a memória para armazenamento dos registros do acervo atingiu sua capacidade máxima. Mesmo assim, o sistema de gerenciamento de coleções desenvolvido por Cabral continuou a ser utilizado, até pelo menos o primeiro semestre de 20I5, tendo passado por modificações, conforme apresentado. No entanto, o sistema estava adaptado apenas para o registro de obras de arte moderna. As obras de arte contemporânea exigiam uma mudança na forma de documentar e, por consequência, na criação de novos recursos no sistema informatizado. Até maio de 2014, aproximadamente metade do acervo era composto de obras de arte contemporânea, tipo de arte que surgiu na década de 1960 e propunha romper com as estruturas tradicionais de arte (pintura, escultura e gravura), e usar novos materiais e técnicas de criação, o que levou à problematização de sua catalogação e impôs a reflexão e reformulação dos processos catalográficos que até então tinham campos específicos para arte moderna ${ }^{21}$. Essa situação ampliou a quantidade e o significado de termos e conceitos da área, elementos básicos para a construção de vocabulário controlado e para a descrição e indexação das obras $^{22}$. Até 2015, quatro funcionários faziam uso da base de dados em Access, os documentalistas Michelle Alencar, Fernando Piola e Cristina Cabral, e Marília Lopes, responsável pelo controle de empréstimo das obras, e a solução encontrada para a continuidade do projeto de atualização do sistema foi dar início à construção de um programa personalizado com o uso da ferramenta gratuita CollectiveAccess ${ }^{23}$.

\section{Catálogos e disseminação do acervo}

O catálogo geral do acervo é um meio para o acesso e disseminação da

19 O MuseumPlus acompanha protocolos como CDWA Lite (Categories for the Description of the Works of Art, do Getty Research Institute), LIDO (Lightweight Information Describing Objects), SPECTRUM e Dublin Core, e diretrizes como as do CIDOC, da Museum Computer Network (MCN), do ICCD (Instituto Centrale per il Catalogo e la Documentazione) e da Canadian Heritage Information Network (CHIN).

20 Arquiteto e docente na Faculdade de Arquitetura e Urbanismo (FAU USP).

21 Além da diversidade de materiais, a arte contemporânea envolve performances, instalações, arte digital e vídeos.

22 Cf. SMIT, 1986.

23 Um fato que chama a atenção é que a Universidade possui uma Superintendência de Tecnologia da Informação (STI) que poderia auxiliar na criação de um sistema informatizado, mas seus serviços não são disponibilizados aos museus sob guarda da USP. 
informação sobre a coleção. Tradicionalmente, os museus elaboravam catálogos impressos, todavia, mais recentemente, os catálogos têm sido elaborados no ambiente digital, o que faz com que as informações sejam atualizadas rapidamente e o alcance do acervo aumente. Conforme visto, o primeiro catálogo geral do acervo do MAC USP foi publicado em 1973. O segundo, coordenado por Aracy Amaral, foi publicado em 1988 e não contemplou todo o acervo. Já o terceiro e último catálogo foi publicado em 1990, ainda na gestão de Ana Mae Barbosa.

Dois projetos de divulgação on-line do acervo foram executados no Museu com o objetivo de torná-lo acessível virtualmente. Daisy Peccinini que coordenou a Divisão Científica a partir de 1994, colocou em prática o primeiro projeto, intitulado "Criação de bases de dados e banco de imagens no MAC USP: pesquisa histórico-crítica e difusão cultural do acervo do MAC USP on-line", entre fevereiro 1997 e maio 1999. Em 2002, na gestão de Elza Ajzenberg, foi estruturado o segundo projeto, desta vez denominado MAC Virtual. Tanto este projeto como o de Peccinini não consideraram o acervo como um todo e ficaram disponíveis on-line temporariamente. Para Magalhães (20I5), em vez de publicar de forma impressa o quarto catálogo geral do Museu, o ideal é fazê-lo no ambiente digital, tal como o Museum of Modern Art de Nova York (MoMA), que investe na ferramenta "Explore the Collection" desde 1993 ou como a Tate Modern, que nunca publicou um catálogo impresso desde sua fundação no ano 2000 , priorizando a produção de monografias de artistas ${ }^{24}$.

\section{Considerações}

Em síntese, a história da documentação do acervo do MAC USP pode ser dividida em três fases. A primeira, de 1948 a 1962, que engloba a documentação feita pelo antigo MAM. A segunda, de 1963 a 1982, caracterizada pela descontinuidade da catalogação do acervo. E a terceira fase que se iniciou em 1983 e segue até o período de estudo coberto por esse artigo, com a informatização do acervo e as duas revisões catalográficas, a primeira em 1985 e a segunda em andamento desde 2008. Pode-se considerar que a atuação de Aracy Amaral foi fundamental para a sistematização da documentação do acervo devido à implantação da Divisão Científica e à consequente informatização do acervo. Além dela, reconhece-se a participação intensa de Lisbeth Ruth Rebollo Gonçalves nesse processo, observada em três momentos, na década de 1980, como coordenadora da Divisão Científica; na sua primeira gestão entre 1994 e 1998 , quando foi estruturado o Setor de Arquivo, e durante sua segunda gestão, entre 2006 e 2010, ao identificar a necessidade de revisão da catalogação do acervo, que teve como consequência a contratação de Ana Gonçalves Magalhães para coordenar esse projeto.

O MAC USP, assim como os demais acervos artísticos do país, deve se inserir no diálogo internacional para fortalecer o debate da documentação museológica no Brasil e, consequentemente, contribuir para a profissionalização dos processos documentais de suas coleções, além de reduzir a lacuna existente entre os museus estrangeiros e os nacionais e garantir uma melhor compreensão sobre a relevância da documentação por parte dos responsáveis pela instituição ${ }^{25}$. Infelizmente, a ausência de políticas institucionais aliada à infraestrutura

24 O catálogo digital permite melhor acompanhamento sobre o crescimento do acervo.

25 Insere-se neste debate o impacto da inovação tecnológica na documentação de acervos museológicos. 


\section{A Organização Informacional do Acervo do Museu de Arte Contemporânea da Universidade de São Paulo}

inadequada e à carência de recursos humanos fazem com que as atividades de documentação do Museu sejam dependentes de verba externa e de trabalho voluntário, uma vez que a gestão da USP mantém os cortes financeiros. Para Chiarelli (20II) e Freire (20I3), as Artes não estão entre os assuntos em pauta pela direção da Universidade, e o MAC USP, com a importância da sua coleção, está em descompasso diante das ações internacionais de documentação e difusão de acervo. $\mathrm{O}$ ambiente econômico e o desapreço exercido pela Universidade não favorecem seu pleno desenvolvimento.

Tornar evidente o valor da informação de forma a conseguir apoio institucional não é tarefa fácil, pois conforme afirmar Smit (1986), a informação é o produto da documentação, que apesar de ser utilizada em diversos setores de um museu e fazer parte de sua dinâmica, seu tratamento é custoso e é um recurso difícil de ser avaliado financeiramente. Entretanto, acredita-se que a ampliação do debate sobre documentação museológica no país irá, aos poucos, mudar a cultura organização dos museus, de maneira a incentivar a implantação de políticas documentais, fortalecer as práticas de documentação, ampliar o acesso à informação sobre os acervos brasileiros e promover sua disseminação.

\section{Referências}

BEVILACQUA, Gabriel. Museus como serviços de informação. In: SEMINÁRIO SERVIÇOS DE INFORMAÇÃO EM MUSEUS, 2., 20I2, São Paulo.Anais... São Paulo: Pinacoteca do Estado de São Paulo, 20 I4. p. I I-I7.

CABRAL, Cristina. Depoimento. São Paulo: MAC USP, dez.20I4. Entrevista concedida à Camila Aparecida da Silva. Entrevista. 2014.

CHIARELLI,Tadeu. A arte, a USP e o devir do MAC. Revista Estudos Avançados, SciELO Brasil, v. 25, n. 73, p. 24I-252, $20 \mathrm{II}$.

FERNANDES, Eva Lieblich. Depoimento. São Paulo, jun.20I0. Entrevista concedida à Ana Gonçalves Magalhães. 2010.

FREIRE, Cristina (org.). Walter Zanini: escrituras críticas. São Paulo:Annablume, 2013.

MAGALHÃES, Ana Gonçalves. Apresentação. In: SEMINÁRIO INTERNACIONAL ARQUIVOS DE MUSEUS E PESQUISA, I., 2009, São Paulo. Anais... São Paulo: MAC USP, 20I0. p. 4-7.

A Narrativa de Arte Moderna no Brasil e as Coleções Matarazzo, MAC USP. Revista Museologia \& Interdisciplinaridade, v. I, n. I, p. 77-I08, jan/jul 2012.

.(Org.) Classicismo, realismo, vanguarda: pintura italiana no entreguerras. São Paulo: MAC USP, 2013.

Depoimento. São Paulo: MAC USP, jan.20I5. Entrevista concedida à Camila Aparecida da Silva. 2015.

MACHADO, Cecília. Como implantar um sistema básico de inventário. In: Il Programa de treinamento em documentação museológica. São Paulo: CIDOC, 2014. 
OTLET, Paul. El tratado de documentación: el libro sobre el libro.Teoría y práctica de Paul Otlet. Murcia: Universidad de Murcia, 2007. Tradução de María Dolores Ayuso García.

SALSZTEIN, Sônia. Depoimento. São Paulo: MAC USP, jan. 20I5. Entrevista concedida à Camila Aparecida da Silva. 2015.

SMIT, Johanna W. O que é documentação. São Paulo: Brasiliense, I 986.

\section{Documentos consultados}

Fichas catalográficas do antigo MAM. Fonte: Seção de Catalogação MAC USP.

Fichas catalográficas do MAC USP. Fonte: Seção de Catalogação MAC USP.

Lista datilografada de Eva Lieblich Fernandes [cópia]. Especificação das obras pertencentes ao acervo do museu, ca. 195 I, I 5 páginas. Fonte: Seção de Catalogação do MAC USP.

Livros de tombo do antigo MAM. Fonte: Seção de Catalogação do MAC USP. 